\title{
Bigger Size Silver Nanoparticles Hamper Mother and Fetus Nutrition after Serial Ingestion of Bolotic Colloidal Nano Silver Stirring Solution through Oral Route: A Revolutionary Research Discovery in Teratogenicity \& Toxicity Field
}

\author{
Pani Jyoti Prakash ${ }^{1^{*}}$ and Singh Royana ${ }^{2}$ \\ ${ }^{1}$ Research Scholar, Department of Anatomy, Institute of Medical Sciences, Banaras Hindu University, Varanasi, Uttar Pradesh, 221005, India \\ ${ }^{2}$ Professor, Department of Anatomy, Institute of Medical Sciences, Banaras Hindu University, Varanasi, Uttar Pradesh, 221005, India
}

*Corresponding author: Jyoti Prakash Pani, Research Scholar, Department of Anatomy, Institute of Medical Sciences, Banaras Hindu University, Varanasi, Uttar Pradesh, India, 221005, Tel: 08433668356; E-mail: jyotiprakash.pani35@gmail.com

Received date: September 01, 2017; Accepted date: November 29, 2017; Published date: December 06, 2017

Copyright: @ 2017 Prakash PJ, et al. This is an open-access article distributed under the terms of the Creative Commons Attribution License, which permits unrestricted use, distribution, and reproduction in any medium, provided the original author and source are credited.

\begin{abstract}
In the field of household products like air conditioner, food protective wrapper silver foil, compressor, fabrics and washing machine manufacture, subscriber or consumer utilized engineered silver nanoparticles of multi bigger size (100 nm size range or more) demand has been extensively increased with increase of negative feedback while using. For the purpose to assess the effect of bigger size silver nano particles on body nutritional status, a serial oral application of silver nanoparticle colloidal stirring cool solution has been made upon pregnant Swiss Albino mice. On serial application (Daily once in morning 9 am continuously from 6 to 19 gestational ages) by repeated gavages during pregnancy pass through portal venous circulation towards liver after gastro intestinal tract absorption hampers mother nutrition by blocking intra hepatic billiary radical and also drastically affect fetal nutrition following same mechanism after crossing blood placental barrier due to gradual accumulation. The present research investigates whether orally induce colloidal silver nanoparticles (AgNps) reach after crossing mother mouse blood placental barrier and induce adverse effects in fetuses from treated group.
\end{abstract}

Pregnant Swiss Albino female mouse from treated group are exposed during the first 13 days of gestation by serial oral bolotic application of bigger size silvernano colloid stirring cool solution at volume of $6,12,18,24 \mathrm{mg} / \mathrm{kg}$ b.w. corresponds to individual group when compared with double distilled water vehicle control. Black ash colored bigger silver nanoparticles are identified scattered in maternal and fetal liver, upper GI tissues, placental and umbilical cord tissues of pregnant mother and fetuses after cesarean section and organ removal in gross , histological and TEM view. Particles are found in chronic depositative manner severely blocking portal triad of liver, IHBR and portovenous route. Transmission electron microscopy coupled with energy-dispersive spectroscopy confirmed the size range of particle silvernano from 71 to $1900 \mathrm{~nm}$ range.

Serial oral ingestion of bigger size AgNps results in increased number of resorbed and malnutriated fetuses associated with reduced mother body and liver (sink \& weak) weight and diet. Increased expression of particle accumulation is also detected in the placental cut section of treated groups. The acquired results indicates bigger size nanosilver are able to reach fetus after crossing the pregnant mouse blood placental barrier and portovenous circulation causing hamper of mother and fetus nutrition by obstruction of micro and macro channels. Henceforth as a conclusion, it is wise to take precaution with respect to oral exposure of bigger size silvernanoparticles during pregnancy.

Keywords: Colloid silvernano; Mother embryo nutrition; Serial oral bolotic exposure; Blood placental barrier; Pregnancy

\section{Introduction}

Silver nano metal is vividly utilized in the fast food such as very thin silver foil wrap covered veg \& non-veg biriyani rice. Produced by the respective manufacturing company. The thin silver foil wrap usually increases the visual attractiveness of fast food and interest in consumer by enhancing his or her hunger when it kept inside glass self for display in hotel. Though it increases the attractiveness of fast food it has no concern with taste. It also maintains texture of food products. To some extent it protects the food from biosphere micro dust pollution. Now a day's fast food shop owner prefers to use this foil in growing percentage. Humans and the environment are, because of this reason exposes to silver. Especially man exposes to silver mainly through oral route while processing and eating this fast food in food preparation table surfaces, in coating components from machinery tools which manufactures fast food. Small size AgNps shows more positive feedback and less negative feedback by dermal application in form of silver ointpaint and toothpastes and extensive utilization in other public demanded industrial sector but large size AgNps shows more negative and less positive feedback because of its non-penetrative and accumulative nature not gain easy access into the body through dermal route. The prior one cause more molecular and cellular damage (DNA and cells organelles) and evokes oxidative stress. The large size AgNps badly affects digestion, absorption and nutrition by accumulating over micro channels [1]. 
Citation: Prakash PJ, Royana S (2017) Bigger Size Silver Nanoparticles Hamper Mother and Fetus Nutrition after Serial Ingestion of Bolotic Colloidal Nano Silver Stirring Solution through Oral Route: A Revolutionary Research Discovery in Teratogenicity \& Toxicity Field. J Nutr Disorders Ther 7: 221. doi:10.4172/2161-0509.1000221

Page 2 of 8

Large size AgNps are less reactive in comparison to small size, small sizes are predominantly considered under ROS generator group whereas large sizes are free radical generating group. Fact based prime level research propounded that large size AgNps causes chondrosomic respiratory chain autophagy and for that regenerate oxygen sensory genus tension [2-9]. Vertebrate primate affecting bacterial stem cells are evidenced to be disrupted by bigger size AgNps and have the capability to arise demolition of reproductive, digestion activities [10]. Still today some specific in-vivo experiments done and the results showed bigger size AgNps have very serious impacts on human being like mal nutrition, atrophy and respiratory ailments which may lead to fatal condition $[11,12]$ this category particles also evokes oxygen sensory genus tension with programmed cell death consequence [13-15] and essential amino acids with proteins demarcated at hypovalemic shock stage due to malnutrition [16].

A recent research on lower group of animal demonstrated that bigger size AgNps causes severe accumulation and damage of GI system and hampers absorption with flow of nutrition to requisite sight [17]. Bigger size AgNps gained entrance into the human body mostly through oral entry portal route and in powdered form it spreads easily in air, soil and water. It can easily uptake by cell in colloidal form and obstructs tissue nutrition after chronic deposition in tissue space [18-20]. There are lot of causes to be dead assure that exposure of bigger size AgNps to GI tract must be taking place in conscious state or unconscious state leads to permanent hamper of nutrition. Bigger size AgNps in colloidal form ingested directly through food material, medical devices and drugs causing disturbances of GI tract and malnutrition syndrome [21,22]. Apart from bigger size AgNps negative feedback its nutrition hamper activity followed by surpassing through entry portovenous route after absorption in GI system needs further investigation and discovery of hidden facts. Present research assignment was conducted to elicit the negative effect of bigger size AgNps on small intestine and other GI system like stomach, duodenum ect.; \& how it permanently disturbs migration of nutrition to ahead structure.

\section{Material \& Methods}

The present research investigates whether orally induce colloidal silver nanoparticles (AgNps) reach after crossing mother mouse blood placental barrier and induce adverse effects in fetuses from treated group. We utilized 10 Sham control and 10 treated pregnant mice for this purpose. Pregnant Swiss Albino female mouse from treated group are exposed during the first 13 days of gestation by serial oral bolotic application of bigger size silvernano colloid stirring cool solution at volume of $6,12,18,24 \mathrm{mg} / \mathrm{kg}$ b.w. corresponds to individual group when compared with double distilled water vehicle control. Pregnant mice were sacrificed by deep ether/chloroform inhalation anesthesia method after keeping in a glass lid enclosed glass transparent jar. When pregnant mouse achieved full unconsciousness the body is removed from glass jar by opening of glass lid.

Further the body is kept ventrally on a flat trey full of paraffin wax. The unconscious body was stabilized and fixed by proper pinning on 4 limbs of pregnant mother in the same ventral position. Then cesarean section done with dissecting scissor along with both right and left horn of gravid uterus is exteriorized and fresh fetuses were removed along with placenta and umbilical cord. Same procedure was done for double distilled water vehicle control and treated group. The fetuses were further separated from placenta and umbilical cord and properly washed in tap water keeping in Petridis. Organs like liver, upper GI, placenta and umbilical cord of pregnant mother and fetuses were collected following dissection cut into 2 pieces by an aseptic and sharp knife. Half of the pieces from all organs were preserved in $10 \%$ formalin solution for 3 to 7 days in respective leveled glass bottles. After 7 days the organs were removed from neck full glass bottles and processed for routine histology for histological view. (Hematoxylin and eosin) [23]. The other halves of the fresh tissues kept in double filtered distilled water were exposed to TEM protocol for transmission electron microscopy view [24]. For gross view remaining part of formalin preserved organs were simply cut transversely by an organ cutting knife and observed by powerful hand lens.

\section{Result}

Transmission electron microscopy coupled with energy-dispersive spectroscopy confirmed the size range of group of particle silver nano from 71 to $1900 \mathrm{~nm}$ range which were found intermixed in colloidal solution through TEM view. On serial application (continuously from 6 to 19 gestational ages) through oral route in colloid stirring and magnetic cool bigger size AgNps (71 to $1900 \mathrm{~nm}$ range)non filtered solution form during pregnancy pass through portal venous circulation towards liver after getting absorbed from upper gastro intestinal tract hampers mother nutrition by blocking intra hepatic billiary radical and also drastically affect fetal nutrition following same mechanism after crossing blood placental barrier due to gradual accumulation.

\section{Reduction in the organ size}

Serial oral ingestion of bigger size AgNps results in increased number of resorbed and malnutriated fetuses associated with reduced mother body and liver (sink \& weak) weight and diet also found insignificant reduction of placental size \& weight.

\section{Resorbed fetuses}

All foetuses exposed to double distilled water vehicle control, 6, 12, $18 \& 24 \mathrm{mg} / \mathrm{kg} /$ day 71 to $1900 \mathrm{~nm}$ size range bigger particles AgNps group were evaluated for sign of body malformation like resorptions and were compared with all foetuses of anionic double distilled water treated vehicle control group. Out of 57 foetuses from $6 \mathrm{mg} / \mathrm{kg} / \mathrm{day}$ AgNps treated 11 were observed resorptions, Out 57 foetuses from 12 $\mathrm{mg} / \mathrm{kg} /$ day AgNps treated group 15 were observed resorptions Out of 57 foetuses from $18 \mathrm{mg} / \mathrm{kg} /$ day AgNps treated group 27 foetuses were observed resorptions. Out of 61 foetuses from $24 \mathrm{mg} / \mathrm{kg} / \mathrm{day}$ AgNps treated group 22 were observed resorptions. Common sign and symptoms of body malformations of foetuses like resorptions were seen in all treated foetuses delivered from treated pregnant mice consistently but the intensity of such was found increased as the dose of bigger size AgNps colloidal solution increases.

\section{Histological view of bigger size silver nanoparticles obstruction in vital organs}

In histological view increased expression of particle accumulation in scattered form is also detected in the liver, placenta and umbilical cord cut section of treated groups. The acquired results indicate bigger size nano silver are able to reach fetus body after crossing the pregnant mouse blood placental barrier then the particles reach liver. Bigger size silver nano particles also reach and obstruct portal triad along with disruption by deposited there. They reach to portal triad of mother and fetus by floating through portovenous circulation causing hamper of 
Citation: Prakash PJ, Royana S (2017) Bigger Size Silver Nanoparticles Hamper Mother and Fetus Nutrition after Serial Ingestion of Bolotic Colloidal Nano Silver Stirring Solution through Oral Route: A Revolutionary Research Discovery in Teratogenicity \& Toxicity Field. J Nutr Disorders Ther 7: 221. doi:10.4172/2161-0509.1000221

Page 3 of 8

mother and fetus nutrition by obstruction of micro and macro channels in liver of mother and fetus. Histological panoramic view of $12 \mathrm{mg} / \mathrm{kg}$ b.w. mother liver also shows scattered lining of particles in intra hepatic biliary radicals with severe congestion which proves particles chronic obstruction following deposition caused to be hampering of nutrition flow to further structure the same thing is more or less observed in treated liver histological panoramic view of fetuses. Histologically placenta and umbilical cord also suffers from same ailment due to bigger size silver nanoparticle obstruction.

\section{TEM view of bigger size silver nanoparticles obstruction in vital organs causing hamper of nutritional flow}

Black ash colored bigger silver nanoparticles are identified scattered in maternal and fetal liver, upper GI tissues intra cellular compartment, placental and umbilical cord tissues intra cellular compartment of pregnant mother and fetuses obstructing nutrition flowing channels after cesarean section and organ removal with proper protocol processing for TEM view.

In transmission electron microscopic view bigger size silver nanoparticles are found in chronic depositative manner severely blocking intra cellular compartment of portal triad of liver, IHBR and portovenous route related tissues obstructing easy flow of nutritional matters through micro and macro channels. In placenta the bigger size silver nanoparticles found blocking intra cellular compartment of cells of Ramus corii and Ramuli corii which blocks the pathway of exchange of nutrition and oxygen between mother and fetus. This type of consequences hampers fetal nutrition and transportation of oxygen to fetus from mother in pre natal stage during 3rd trimester of pregnancy causing birth of mal-nutrition syndromes like Amelia, snot anomalies, polydactyl, cleft lip and cleft palate, IUGR, resorption, down syndrome, cerebellar ataxias with handicapped and embryological remnant fetuses. Blocking of bigger size silver nanoparticles also observed in intra cellular compartment of cells of Wharton's jelly, umbilical vessels related tissues in TEM view.

\section{Discussion}

In this present research work, we have tried to investigate in details the negative and obstructive effects of serial potential oral bolotic application of bigger size AgNps (71 to $1900 \mathrm{~nm}$ size range) cool and stirring colloidal non filtered solution on the nutritional flow tendency capability of micro and macro channels in liver, intra hepatic billiary radicals, portovenous circulation, portal triad, upper GI tract, placenta and umbilical cord tissue and intra cellular compartment of pregnant Swiss Albino mice and their fresh born fetuses from double distilled water vehicle control and $6,12,18,24 \mathrm{mg} / \mathrm{kg}$ b.w. treated group.

The liver histology shows multiple hepatocyte rows are which arranged in cords and plates manner. In between each rows of cords and plates sinusoid present its endothelium is lined by Kuffer cells. Two spaces space of Disse and Space of Mall present in liver. Space of Disse is present in sub capsular region where Space of Mall present at the endothelium of sinusoid. Porta hepatis is also called "Portal triad" because it receives hepatic artery portal vein and bile duct. The histology of upper GI and it's including viscera's shows lining of simple columnar epithelium. Multiple microvilli were found projected on the lumen side of each epithelial cell. Enterocytes are found extended from each microvillus's cytoplasm. Striated like view is appeared from border of each microvilli called "terminal bar".
The normal placenta histology demonstrates, Basal Plate is the Maternal Surface where Anchoring villis get inserted into maternal endometrium. Intermediate trophoblasts in invasive state are seen here. Chorionic Plate is the Fetal surface from where stem villi arises from umbilical vessels surrounded by connective tissue and fibrin covered by a layer of amnion and chorion. Placental villi capillaries, fetal macrophages (Hofbauer cells) and fibroblasts surrounded by trophoblast and syncytiotrophoblast layers. This is the site which performs gaseous exchange and waste elimination.

Each of whole unit is called Ramus corii which is made up of multiple Ramuli corii. The primary stem villi divides into multiple segments and give off secondary stem villi which further divide into tertiary stem villi, which form the placental lobules and insert into the basal plate. (Ramus corii) They then give off branches to form the terminal villous units. (Ramuli corii) Cells are called Cytotrophoblast present in early gestation; differentiates into villous or extra villous trophoblast and forms Syncytiotrophoblasts by fusing on villous surface. They are inconspicuous in term of placenta. Micro, small \& round mononuclear cells with distinct cell border, minimal clear or eosinophilic cytoplasm and single vesicular nuclei.

Intermediate implantation site and extra villous (X-cells) trophoblasts it infiltrate deciduas and myometrium of placental site, invade and replace spiral arteries of the basal plate to establish maternal-fetal circulation and keep vessels patent which form trophoblastic shell. Micro stage which are located in the basal plate, septa and Chorion Lavae; morphology varies by location. In the basal plate, they are enlarged polyhedral to spindle cells with abundant amphophilic and vacuolated cytoplasmic and large, hyper chromatic nuclei and may resemble adjacent deciduas. In myometrium are more spindled and resemble adjacent smooth muscle cells; may fuse to become multinucleated cells.

Intermediate villous trophoblast which forms the inner layer of the villous trophoblastic mantle. Micro stage which are found larger than cytotrophoblasts, polygonal, abundant clear or eosinophilic cytoplasm, distinct cell borders and single nuclei. Syncytiotrophoblast form the outer layer of the villous trophoblastic mantle. Micro multinucleated giant cells with abundant eosinophilic or basophilic cytoplasm, often with multiple intracytoplasmic vacuoles and dense pyknotic nuclei. Hofbauer cells are also called as fetal macrophages located in villous stroma. Micro cells are round-to-ovoid cells with eccentric nuclei and granular cytoplasm.

The umbilical cord is mostly made up of connective tissue known as Wharton's Jelly and has relatively few cells. The cord has one large umbilical vein and two umbilical arteries. These vessels transport blood to and from the placenta, where exchange between the mother and fetus takes place. In the present study, we observed the maternal and fetal nutrition rate after serial administration (6 to 19 gestational ages) of bigger size AgNps (71 to $1900 \mathrm{~nm}$ range) colloidal stirring cool solution, In histological view we found severe block at intra hepatic billiary radicals, portal triad related tissues in liver even central vein is found to be blocked and congested due to chronic deposition of bigger size silver nanoparticles, The Ramus corii, Ramuli corii, Basal plate, Chorionic plate, Anchoring villi, stem villi, all Hofbauer cells and micro channels of Synciciotrophoblast, Cytotrophastic layers found congested and blocked due to gradual accumulation of black ash colored bigger size silver nano particles, The organs of upper GI tract and umbilical cord also suffers from same pathology. 
Citation: Prakash PJ, Royana S (2017) Bigger Size Silver Nanoparticles Hamper Mother and Fetus Nutrition after Serial Ingestion of Bolotic Colloidal Nano Silver Stirring Solution through Oral Route: A Revolutionary Research Discovery in Teratogenicity \& Toxicity Field. J Nutr Disorders Ther 7: 221. doi:10.4172/2161-0509.1000221

Page 4 of 8

In gross analysis we found reduction in size and weight of mother and fetus liver in increased intensity in group and dose wise manner. (Figures 1 and 2; Table 1) We also found decrease liver weight, decrease body weight and decrease liver weight to body weight ratio in groups corresponds to increasing dose of bigger size AgNps colloid solution $(\mathrm{p}<0.005 ; \mathrm{F}=164.457)$.

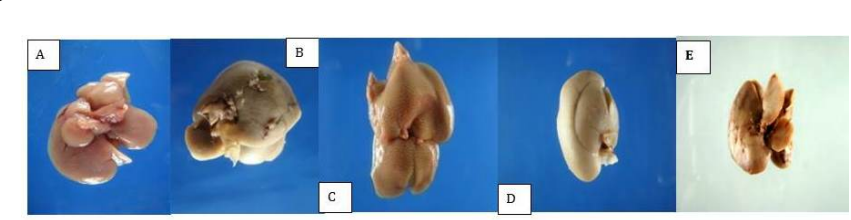

Figure 1(A-E): Pregnant mother dissected liver from double distilled water vehicle control and 6, 12, 18, $24 \mathrm{mg} / \mathrm{kg} / \mathrm{b} . \mathrm{w}$ AgNps treated group.

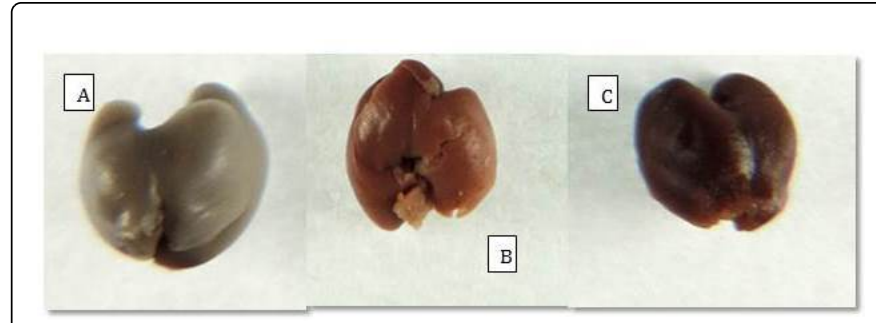

Figure 2: A. Control fetuses' liver B. $12 \mathrm{mg} / \mathrm{kg}$ b.w. AgNps treated group fetuses' liver C. $18 \mathrm{mg} / \mathrm{kg}$ b.w. AgNps treated group fetuses' liver.

\begin{tabular}{|c|c|c|c|c|c|c|c|c|}
\hline Group & Number(N) & $\begin{array}{l}\text { Liver } \\
\text { weight(g) }\end{array}$ & $\begin{array}{l}\text { Body weight (g) G.D. } \\
0 \text { to G.D.18 }\end{array}$ & $\begin{array}{l}\text { Liver to Body } \\
\text { wt.ratio }\end{array}$ & $F$ value & df1,df2 & $P$ value & $\begin{array}{l}\text { Dunnett2-sided } \\
\text { test(Sig.) }\end{array}$ \\
\hline Control & 15 & $3.627 \pm 0.18$ & $38.34 \mathrm{E} \pm 5.24$ & 0.094 & 164.457 & & & \\
\hline $6 \mathrm{mg}$ & 8 & $\begin{array}{ll}3.251 & \pm \\
0.027 & \end{array}$ & $37.62 \mathrm{E} \pm 4.23$ & 0.0865 & & 2,27 & $\begin{array}{l}1 \mathrm{vs} 2,3,4,5<0 \\
.0010 .005\end{array}$ & \\
\hline $12 \mathrm{mg}$ & 7 & $\begin{array}{ll}2.843 & \pm \\
0.061 & \end{array}$ & $37.40 \mathrm{E} \pm 3.81$ & 0.0763 & & & & \\
\hline $18 \mathrm{mg}$ & 8 & $\begin{array}{ll}2.467 & \pm \\
0.075 & \end{array}$ & $37.18 \mathrm{E} \pm 3.39$ & 0.0666 & & & & \\
\hline $24 \mathrm{mg}$ & 7 & $\begin{array}{ll}2.091 & \pm \\
0.075 & \end{array}$ & $36.96 \mathrm{E} \pm 2.97$ & 0.0569 & & & & \\
\hline
\end{tabular}

Table 1: Mean of liver weights, mean body weight and liver weight to body weight ratio of pregnant mother.

While investigating placental morphology and weight we found reduction in placental size in $18 \mathrm{mg}$ treated group (Figure $3 \mathrm{~A}$ ) when viewed and compared with control (Figure $3 \mathrm{~B}$ ). We also found insignificant reduction of placental breadth and pregnant mice liver length \& breadth in increasing dose sequence of colloidal silver nano solution through oral ingestion (Table 2).

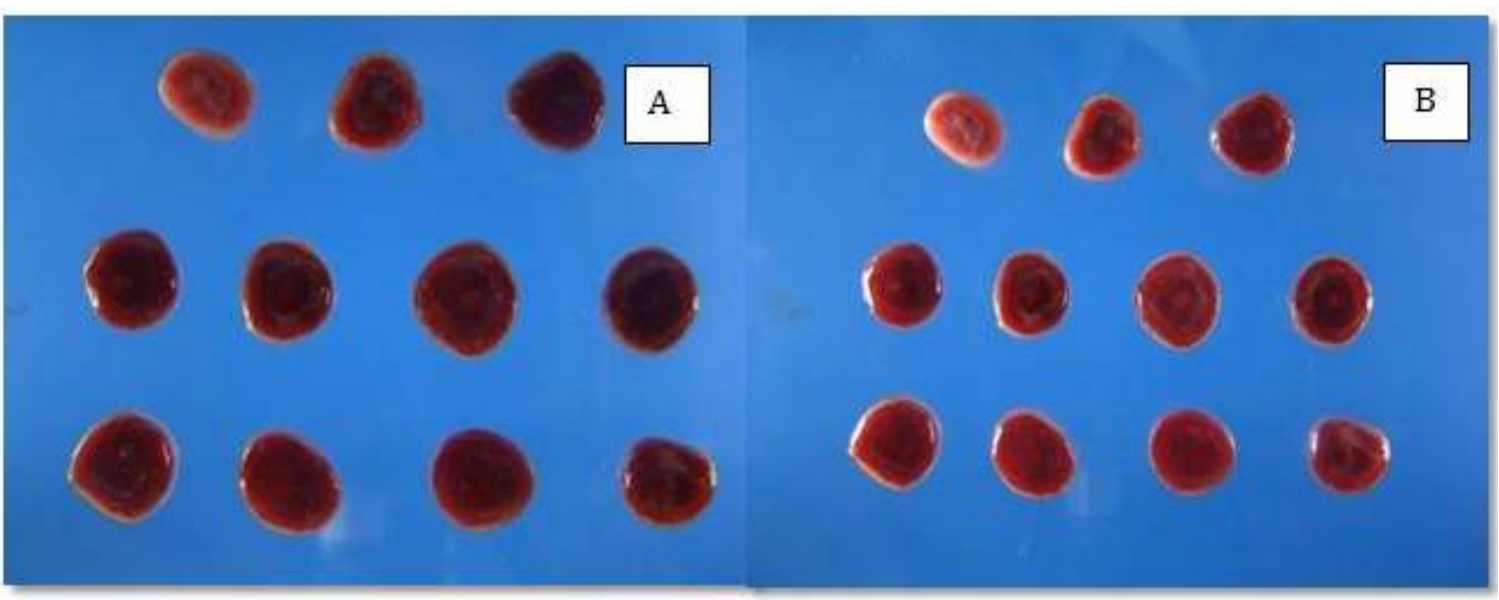

Figure 3: Placenta collected from the pregnant mother delivered pups A. Control Mice placenta B. $18 \mathrm{mg} / \mathrm{kg} / \mathrm{b} . \mathrm{w}$. AgNps treated group placenta. 
Citation: Prakash PJ, Royana S (2017) Bigger Size Silver Nanoparticles Hamper Mother and Fetus Nutrition after Serial Ingestion of Bolotic Colloidal Nano Silver Stirring Solution through Oral Route: A Revolutionary Research Discovery in Teratogenicity \& Toxicity Field. J Nutr Disorders Ther 7: 221. doi:10.4172/2161-0509.1000221

Page 5 of 8

\begin{tabular}{|l|l|l|l|}
\hline \multirow{2}{*}{$\begin{array}{l}\text { Group } \\
\mathbf{S}\end{array}$} & $\begin{array}{l}\text { Pregnant mice } \\
\text { liver }\end{array}$ & $\begin{array}{l}\text { Pregnant mice } \\
\text { liver }\end{array}$ & $\begin{array}{l}\text { Pregnant } \\
\text { placenta }\end{array}$ \\
\cline { 2 - 4 } & Length in cm. & Breadth in cm. & Breadth in cm \\
\hline Control & $4.12 \pm 0.12$ & $3.01 \pm 0.09$ & $1.81 \pm 0.06$ \\
\hline $6 \mathrm{mg}$ & $3.93 \pm 0.08$ & $2.92 \pm 0.03$ & $1.79 \pm 0.04$ \\
\hline $12 \mathrm{mg}$ & $3.92 \pm 0.06$ & $2.90 \pm 0.03$ & $1.75 \pm 0.04$ \\
\hline $18 \mathrm{mg}$ & $3.62 \pm 0.04$ & $2.58 \pm 0.06$ & $1.56 \pm 0.03$ \\
\hline $24 \mathrm{mg}$. & $3.93 \pm 0.02$ & $2.87 \pm 0.06$ & $1.73 \pm 0.03$ \\
\hline
\end{tabular}

Table 2: Different anthropometrical measures of liver \& placentas from control and treated group pregnant mother parameters taken length and breadth in $\mathrm{cm}$ (liver) and breadth distance in $\mathrm{cm}$ (placenta).

When we investigate the resorbed fetus corresponding to dose we found with increase of dose of bigger size silver nanoparticles colloidal solution in group wise manner the percentage of resorbed fetuses also increased (Table 3; Graph 1; Figure 4).

\begin{tabular}{|l|l|l|}
\hline Groups & Fetus resorptions ( Total no. of fetuses) & Percentages \\
\hline Control group & a) Resorptions (2) & a) $3.70 \%$ \\
\hline $\mathbf{6} \mathbf{~ m g}$ & b) Resorptions(11) & c) $18.54 \%$ \\
\hline $\mathbf{1 2} \mathbf{~ m g}$ & c) Resorptions (15) & d) $24.80 \%$ \\
\hline $\mathbf{1 8} \mathbf{~ m g}$ & d) Resorptions (27) & c) $45.10 \%$ \\
\hline $\mathbf{2 4} \mathbf{~ m g}$ & e) Resorptions (22) & c) $33.50 \%$ \\
\hline
\end{tabular}

Table 3: Number and percentages of resorptions from control and all treated group.

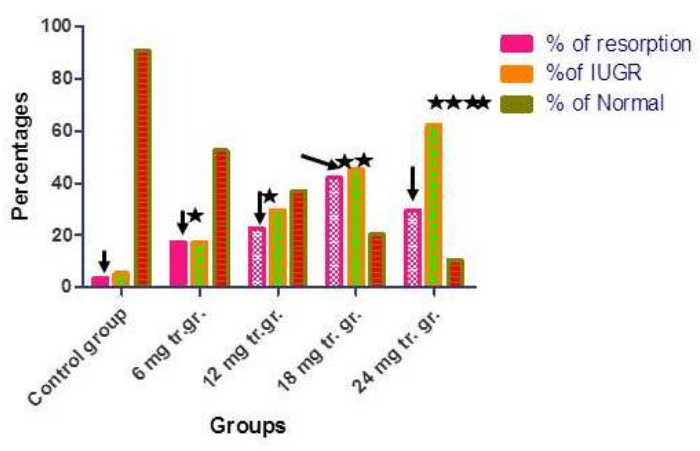

Graph 1: Resorbed fetus.

When we investigate the gross appearance of umbilical cord we saw the lumen of cut section of umbilical cords from treated group shows multiple black ash colored bead dots which proved persistent of bigger size AgNps obstruction while passing through it. The histology of liver tissue of pregnant mother and their delivered fetuses from treated group revealed bigger size silver nano-particles also reach and obstruct portal triad along with doing disruption by depositing there.

Figure 4: Resorbed and Severe IUGR fetuses with placenta from 18 $\mathrm{mg} / \mathrm{kg}$ b.w. AgNps treated group.

They reach to portal triad of mother and fetus by floating through portovenous circulation causing hamper of mother and fetus nutrition by obstruction of micro and macro channels in liver of mother and fetus. Histological panoramic view of $12 \mathrm{mg} / \mathrm{kg}$ b.w. mother liver also showed scattered lining of particles in intra hepatic biliary radicals with severe congestion which proves particles chronic obstruction following deposition caused to be hampering of nutrition flow to further structure the same thing is more or less observed in treated liver histological panoramic view of fetuses (Figures 5 and 6).

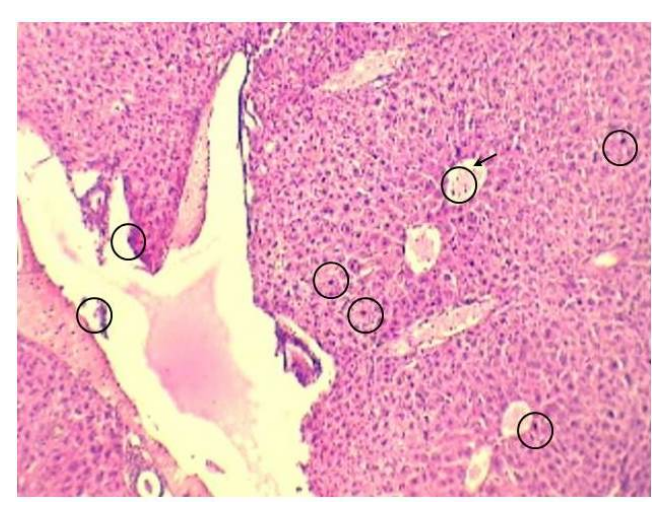

Figure 5: Panoramic view of $12 \mathrm{mg} / \mathrm{kg}$ b.w. bigger size AgNps treated pregnant mother liver histology showing disrupted portal triad with severe congested intra hepatic biliary radicals and scattered distributed silver nanoparticles in histology matrix. The histology also shows particle interference in central vein in floating stage (Arrow indicated to black circle).

Histologically placenta and umbilical cord also suffers from same ailment due to bigger size silver nanoparticle obstruction. Histology of placenta showed Basal Plate dysmorphology \& loss of some portion with partial over ride of bigger particles, Chorionic Plate degeneration and disruption. Placental villi capillaries, fetal macrophages (Hofbauer cells) and fibroblasts surrounded by trophoblast and syncytiotrophoblast layers showed severely destructed, hurt, weak and over-ride of black ash colored bigger size silver nanoparticles. The act of gaseous exchange and waste elimination with flow of nutrition to further part in hampered due to congestion and blocking by bigger particles. 
Citation: Prakash PJ, Royana S (2017) Bigger Size Silver Nanoparticles Hamper Mother and Fetus Nutrition after Serial Ingestion of Bolotic Colloidal Nano Silver Stirring Solution through Oral Route: A Revolutionary Research Discovery in Teratogenicity \& Toxicity Field. J Nutr Disorders Ther 7: 221. doi:10.4172/2161-0509.1000221

Page 6 of 8

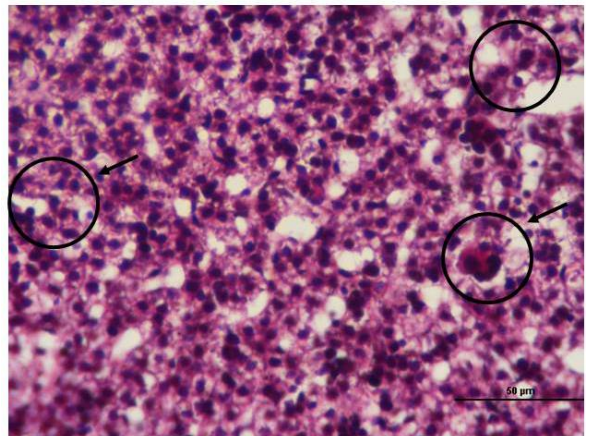

Figure 6: Panoramic view of $12 \mathrm{mg} / \mathrm{kg}$ b.w. bigger size AgNps treated fetus liver histology showing severe congested intra hepatic billiary radicals and scattered distributed silver nanoparticles in histology matrix. The histology also shows particle interference in central vein in floating stage (Arrow indicated to black circle).

Ramus corii \& Ramuli corii found distorted. The anchoring villis \& primary stem villi found distorted. Cytotrophoblast and Syncytiotrophoblasts found distorted. Micro stage which are found larger than cytotrophoblasts, polygonal, abundant clear or eosinophilic cytoplasm, distinct cell borders and single nuclei in treated group cytotrophoblast found in weak sink and distrusted stage with penetration of black ash colored silver nanoparticles. Syncytiotrophoblast which form the outer layer of the villous trophoblastic mantle are found in disrupted stage due to overriding and penetration of bigger size silver nanoparticles in treated groups in increasing intensity manner with increase dose group (Figure 7).

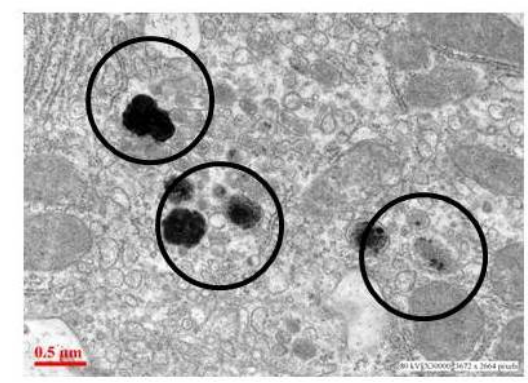

Figure 7: $0.5 \mu \mathrm{m}$ (500,000 magnification) TEM view of fetal liver tissue showing obstruction of bigger silver nanoparticles inside mitochondria, lysosome, endocytotic vesicle and rough endoplasmic reticulum in blocking stage to the nutritional flowing micro channels due to chronic deposition.

Micro stage also which are nothing but multinucleated giant cells with abundant eosinophilic or basophilic cytoplasm, often with multiple intracytoplasmic vacuoles and dense pyknotic nuclei are found in dysmorphic stage with loss of part of it and bigger particles silver nano found completely filled intracytoplasmic vacuoles. Hofbauer cells are also called as fetal macrophages located in villous stroma are found in atrophic and blocking with disruption stage due to same pathophysiology. Micro cells which are round-to-ovoid cells found partial loss of normal structure with eccentric nuclei and granular cytoplasm are found in dysmorphic state.

The histology of cut section of umbilical cord shows discontinuity of connective tissue in matrix. Wharton's Jelly which has relatively few cells found histologically changed to black colored and ash colored with scattered spread of bigger size AgNps in its matrix. The histology of cut section of one umbilical vein showed penetration of bigger size particles in the lumen which is found in obstructive stage and same thing is observed in histology of cut section of two umbilical arteries. The same histological changes observed in upper GI organs. Transmission Electron Microscopy features also revealed Black ash colored bigger silver nanoparticles are identified scattered in maternal and fetal liver, upper GI tissues intra cellular compartment, placental and umbilical cord tissues intra cellular compartment of pregnant mother and fetuses obstructing nutrition flowing channels.

In the same view bigger size silver nanoparticles are found in chronic depositative manner severely blocking intra cellular compartment of portal triad of liver, IHBR and portovenous route related tissues obstructing easy flow of nutritional matters through micro and macro channels. In placenta the bigger size silver nanoparticles found blocking intra cellular compartment of cells of Ramus corii and Ramuli corii which blocks the pathway of exchange of nutrition and oxygen between mother and fetus. This type of consequences hampers fetal nutrition and transportation of oxygen to fetus from mother in pre natal stage during 3rd trimester of pregnancy causing birth of mal-nutrition syndromes like Amelia, snot anomalies, polydactyl, cleft lip and cleft palate, IUGR, resorption, down syndrome, cerebellar ataxias with handicapped and embryological remnant fetuses.

Blocking of bigger size silver nanoparticles also observed in intra cellular compartment of cells of Wharton's jelly, umbilical vessels related tissues in TEM view. The microvilli of upper GI tract in TEM view were seen in completely disrupted and broken stage or in partial loss stage, which indicates that bigger size AgNps can surpasses the protective barrier of the upper GI tract \& small intestine i.e. the upper GI acidic, alkali \& neutral mucins which cause impairment and destruction to the microvilli.

The gross finding which is present in result section from it, we can explain the significant decrease in body weight, liver weight, and liver weight to body weight ratio of bigger size AgNps treated mice. Absorption of fine food is the main activity of upper GI tract organs and distal 2/3rd of duodenum, jejunum and ileum. Due to the complete disruption and partial loss with absence of microvilli of enterocytes, the surface area absorption of the upper GI organ and distal 2/3rd of duodenum, jejunum and ileum (small intestine) was reduced markedly which ultimately led to decrease in the absorption of nutrient materials, accumulation of unabsorptive nutrients and hamper of nutritional status resulting in a reduction in the body weight, liver weight and liver weight to body weight ratio of Pregnant Swiss Albino mice and their fetuses. In our study, we observed the gross structural transmission electron microscopically and histological disruptive changes in the microvillus of extended enterocytes of organs of upper GI and small intestine, protovenous route, portal triad, Ramus corii, Ramuli corii, basal and maternal plates with all cells of placenta and all histological parts of umbilical cord i.e. loss of microvilli, and disruption of other structure which may give passage to bigger size AgNps for entering and abnormally subjected to accumulation into the intestinal wall and then hence into the portal circulation and systemic circulation which results in hamper of nutritional flow. After more 
Citation: Prakash PJ, Royana S (2017) Bigger Size Silver Nanoparticles Hamper Mother and Fetus Nutrition after Serial Ingestion of Bolotic Colloidal Nano Silver Stirring Solution through Oral Route: A Revolutionary Research Discovery in Teratogenicity \& Toxicity Field. J Nutr Disorders Ther 7: 221. doi:10.4172/2161-0509.1000221

Page 7 of 8

than 20 days of serial oral route administration of bigger size AgNps colloidal cool and stirring solution, a dose-dependent increased accumulation and deposition of bigger size AgNps was also observed in the lamina propria in both the small and large intestine of primate vertebrate; lower group of animal of category Sprague-Dawley rats which is found suppressing nutritional activity with frequent cell shedding or weak and sink cell at the tip of the villi in upper GI organs with distal 2/3rd of duodenum, jejunum and ileum (small intestine) [25].

In the recent days, scientists also reported persistent of bigger size AgNps nano granules in the intestinal system of lower group of animal of category Sprague-Dawley rats after more than 20 days serial oral bolus exposure of large size AgNps in form of colloidal and cool stirring solution or to silver acetate to lower group of animal of category Sprague-Dawley rats hampering normal activity of nutrition and flow rate [26]. Similarly, in this present study, bigger size AgNps were found persisted and obstructed in the various layers of organs of upper GI and distal 2/3rd of duodenum, jejunum and ileum (small intestine) including broken, absent and disrupted microvilli of extended enterocytes and other organ's disrupted histological status causing hamper of nutrition due to obstruction of normal flow of nutritional matter to ahead structure. Because of penetration of bigger size AgNps in shrunken lumen of upper GI organs, distal 2/3rd of duodenum, jejunum and ileum, portal triad of liver, portal circulation, micro channels of histological features of placenta and histological features of lumen of umbilical cord a few distorted microvilli found bead dot like swelling structure and loss of nutritional flow to further part.

Furthermore, in bigger size AgNps treated experimental mice; the intestinal absorptive cells as well as cells of other organ concern with nutrition were found to be badly damaged, disrupted, partial absence and part broken stage. In past few studies conducted in broiler and layer chickens suggested that silver and gold nanoparticles neither improved nor depressed embryonic growth due to neither hamper fetal nutrition nor enhances fetal nutrition [27], but affected embryo organ size due to hampering embryo nutrition [28]. In this study, NanoAg of bigger size injected mothers and their fresh delivered embryos in Swiss Albino mice and their fetuses had a lower liver weight, lower body weight and gradually reducing liver weight to body weight ratio in increasing dose group. Some of the young researcher showed after their experiment that silver (especially in the form of nanoparticles) had negative effects on liver weight [29]. The cause of hampering nutrition in mother and fetus treated with bigger size silver nanoparticles in serial oral ingestion of bigger size AgNps in colloidal stirring solution form is obstruction of these bigger particles in nutritive flow channels. Once the channels are blocked the nutrition is hampered to further part. It needs further exploration of facts that how these consequences are controlled and become ameliorative in spite of disruptive.

\section{Conclusion}

Based on our results, it is documented that bigger size AgNps somehow interact and block nutritive flow channels of microvilli inside extended enterocytes of the upper GI tract organs and small intestine, also intestinal absorptive cells causing structural and histological changes, resulting in the alteration of cell membrane penetrative capacity and finally destruction and disruption of the microvilli which led to hamper of nutrition in liver, upper GI tract organs and small intestine of mothers and fetuses from bigger size AgNps treated group also placenta and umbilical cord of mother seen obstructive sign by black ash colored bigger size AgNps and led to hamper of nutrition. Subsequently, the GI tract epithelium gets destroyed and is the reason for the decrease in body weight, liver weight \& liver weight to body weight ratio of experimental mice. We thus conclude that AgNps destroy the mucosa of small intestine and impede its nutritive flow function. Henceforth as a conclusion, it is wise to take precaution with respect to oral exposure of bigger size silver nanoparticles during pregnancy.

\section{Declaration of Interest}

Authors have no conflict of interest.

\section{References}

1. Chen X and Schluesener HJ (2007) Nanosilver: a nanoproduct in medical application. Toxicol Lett 176: 1-12.

2. Ahamed M, Karns M, Goodson M, Rowe J, Hussain SM, et al. (2008) DNA damage response to different surface chemistry of silver nanoparticles in mammalian cells. Toxicol Appl Pharmacol 233: 404-410.

3. Arora S, Jain J, Rajwade JM, Paknikar KM (2008) Cellular responses induced by silver nanoparticles: In vitro studies. Toxicol Lett 179: 93-100.

4. Arora S, Jain J, Rajwade JM, Paknikar KM (2009) Interactions of silver nanoparticles with primary mouse fibroblasts and liver cells. Toxicol Appl Pharm 236: 310-318.

5. Asharani PV, KahMun GL, Hande MP, Valiyaveettil S (2009) Cytotoxicity and genotoxicity of silver nanoparticles in human cells. ACS Nano 3: 279-290.

6. Carlson C, Hussain SM, Schrand AM, Braydich-Stolle LK, Hess KL, et al. (2008) Unique cellular interaction of silver nanoparticles: size-dependent generation of reactive oxygen species. J Phys Chem B 112: 13608-13619.

7. Hussain SM, Hess KL, Gearhart JM, Geiss KT, Schlager JJ (2005) In vitro toxicity of nanoparticles in BRL 3A rat liver cells. Toxicol In Vitro 19: 975-983.

8. Kim S, Ryu DY (2013) Silver nanoparticle induced oxidative stress, genotoxicity and apoptosis in cultured cells and animal tissues. J Appl Toxicol 33: 78-89.

9. Kim S, Choi JE, Choi J, Chung KH, Park K, et al. (2009) Oxidative stressdependent toxicity of silver nanoparticles in human hepatoma cells. Toxicol in Vitro 23: 1076-1084.

10. Liu X, Lee PY, Ho CM, Lui VCH, Chen Y, et al. (2010) Silver nanoparticles mediate differential responses in keratinocytes and fibroblasts during skin wound healing. Chem Med Chem 5: 468-475.

11. Posgai R, McCulloch CBC, Murphy KR, Hussain SM, et al. (2011) Differential toxicity of silver and titanium dioxide nanoparticles on Drosophila melanogaster development, reproductive effort, and viability: Size, coatings and antioxidants matter. Chemosphere 85: 34-42.

12. Wu Y, Zhou Q, Li H, Liu W, Wang T, et al. (2009) Effects of silver nanoparticles on the development and histopathology biomarkers of Japanese medaka (Oryziaslatipes) using the partial-life test. Aquat Toxicol 100: 160-167.

13. Ahamed M, Posgai R, Gorey TJ, Nielsen M, Hussain SM, et al. (2010) Silver nanoparticles induced heat shock protein 70 , oxidative stress and apoptosis in Drosophila melanogaster. Toxicol Appl Pharmacol 242: 263-269.

14. Asharani PV, Wu YL, Gong Z (2008) Toxicity of silver nanoparticles in zebra fish models. Nanotechnology 19: 1-8.

15. Choi JE, Kim S, Ahn JH, Youn P, Kang JS, et al. (2010) Induction of oxidative stress and apoptosis by silver nanoparticles in the liver of adult zebra fish. Aquat Toxicol 100: 151-159.

16. Prabhu S, Poulose EK (2012) Silver nanoparticles: mechanism of antimicrobial action, synthesis, medical applications and toxicity effects. International nano letters; $2: 32$. 
Citation: Prakash PJ, Royana S (2017) Bigger Size Silver Nanoparticles Hamper Mother and Fetus Nutrition after Serial Ingestion of Bolotic Colloidal Nano Silver Stirring Solution through Oral Route: A Revolutionary Research Discovery in Teratogenicity \& Toxicity Field. J Nutr Disorders Ther 7: 221. doi:10.4172/2161-0509.1000221

Page 8 of 8

17. Sung J, Ji J, Yoon JU, Kim DS, Song MY, et al. (2008) Lung function changes in Sprague-Dawley rats after prolonged inhalation exposure to silver nanoparticles. Inhal Toxicol 20: 567-574.

18. Florence AT (1997) The oral absorption of micro- and nanoparticulates: neither exceptional nor unusual. Pharmaceut Res 14: 259-266.

19. Florence AT, Hussain N (2001) Transcytosis of nanoparticle anddendrimer delivery systems: evolving vistas. Adv Drug Deliv Rev 50: S69-89.

20. Jeong GN, Jo UB, Ryu HY, Kim YS, Song KS, et al. (2010) Histochemical study of intestinal mucins after administration of silver nanoparticles in Sprague-Dawley rats. Arch Toxicol 84: 63-69.

21. Oberdorster G, Maynard A, ILSI Research Foundation/Risk Science Institute Nanomaterial Toxicity Screening Working Group (2005) Principles for characterizing the potential human health effects from exposure to nanomaterials: elements of a screening strategy. Part Fibre Toxicol 2: 8 .

22. Peters A, Wichmann HE, Tuch T (1997) Respiratory effects are associated with the number of ultrafine particles. Am J of Resp Crit Care. 155: 1376-1383.
23. Drury RAB, Wallington EA Carlton's Histological techniques; (5th edition).

24. Reimer L (1997) Transmission Electron Microscopy: Image Formation and Microanalysis (4th edsn) Berlin: Springer.

25. Jeong GN, Jo UB, Ryu HY, Kim YS, Song KS, et al. (2010) Histochemical study of intestinal mucins after administration of silver nanoparticles in Sprague-Dawley rats. Arch Toxicol 84: 63-69.

26. Loeschner K, Hadrup N, Qvortrup K, Larsen A, Gao X, et al. (2011) Distribution of silver in rats following 28 days of repeated oral exposure to silver nanoparticles or silver acetate. Part Fibre Toxicol 8: 18-42.

27. Pineda L, Sawosz E, Hotowy A, Elnif J, Sawosz F, et al. (2012) Effect of nanoparticles of silver and gold on metabolic rate and development of broiler and layer embryos. Comp Biochem Physiol A 161: 315-319.

28. Pineda L, Chwaliboga A, Sawosz E, Lauridsen C, Engberg R, et al. (2012) Effect of silver nanoparticles on growth performance; metabolism and microbial profile of broiler chickens. Arch Anim Nutr 66: 416-429.

29. Andi MA, Mohsen H, Farhad A (2011) Effects of feed type with/without nanosil on cumulative performance: Relative organ weight and some blood parameters of broilers. Glob Vet 7: 605-609. 